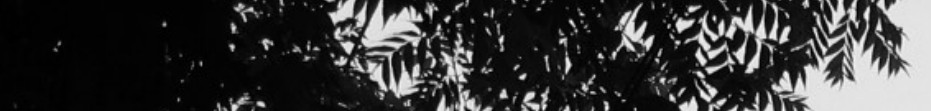

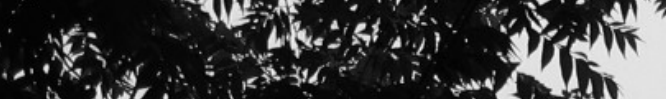

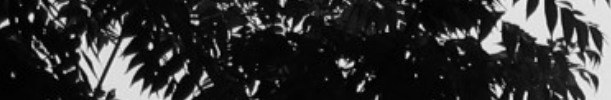

$\because y^{2}$

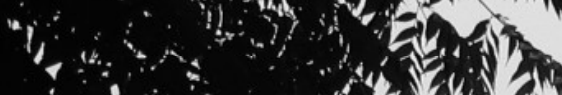

(1)

n

- 1 .

(3) 3 in

(

3

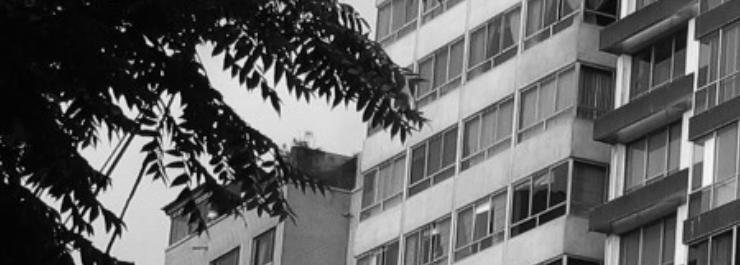

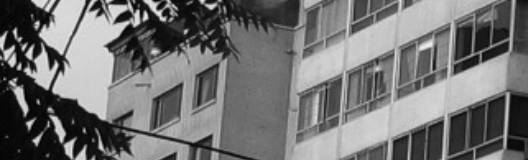

senin id

( 100

- Ficill

*⿻一𠃋?

1.111

(1)

4 管四1

IDIII

1101

mond

QIIIII)

17] IIIIII||

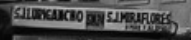

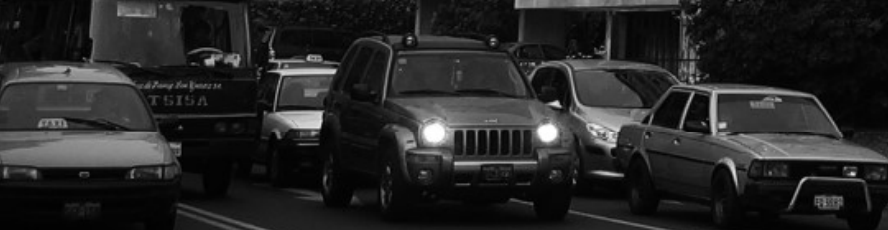

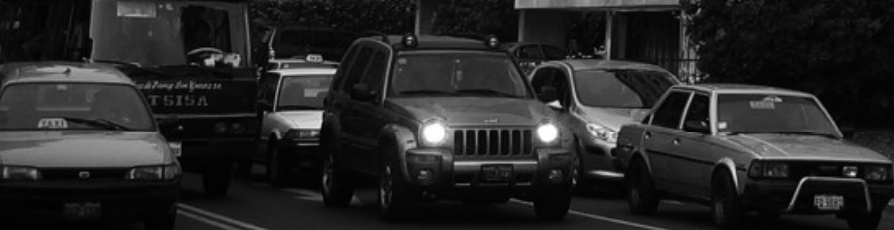

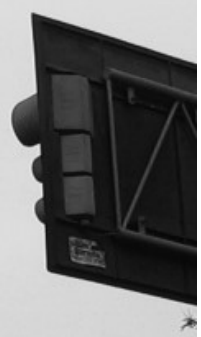

\title{
La identidad
}

de la arquitectura residencial multifamiliar

contemporánea en Lima

Juan de Dios Salas 


\section{Presentación}

En años recientes, el intento de convertir en masiva la producción residencial inmobiliaria de Lima, por medio de la ampliación de las facilidades de acceso al crédito hipotecario, la publicidad, la germinación de una nueva psicología del consumo, las políticas gubernamentales en materia de vivienda, los cambios normativos de densidad, entre otros factores, ha generando una expedita y perceptible alteración del paisaje urbano limeño. Esta alteración del paisaje se evidencia en los procesos de rezonificación de usos del suelo de extensas áreas de Lima metropolitana y los consiguientes procesos de densificación. Son precisamente los efectos de estos procesos los que han dado lugar a la extendida aparición de tipologías edificatorias residenciales de alta densidad. La respuesta a la interrogante de si estas tipologías representan esfuerzos locales o si son adaptaciones de modelos ya producidos en otros lugares, es lo que da origen al presente trabajo. En este artículo se ha ensayado una comparación desaprensiva de la oferta inmobiliaria de tres mercados diferentes: Bogotá, Santiago y Lima, con el propósito de confirmar o refutar la subjetiva percepción que la presunta identidad de la arquitectura residencial multifamiliar limeña no es nada más que la adaptación y reproducción de un menú de imágenes que la globalización provee a través de la homogeneidad de su lenguaje y de sus mecanismos comunicacionales.

\section{Preámbulo}

\section{A fructibus cognoscitur arbor}

Meses atrás, a propósito del tema de una conversación sobre una presunta burbuja inmobiliaria que se estaría presentando en Lima metropolitana y de las señales de la ralentización del mercado de bienes raíces, reflexionábamos si existiría una arquitectura residencial multifamiliar contemporánea propia de Lima. La interrogante es francamente pertinente al tratarse de un asunto de identidad, es decir de si lo fabricado es o no percibido como perteneciente al lugar por la colectividad limeña. Una respuesta expedita, basada en nuestra percepción subjetiva del tema, pareciera ser simple: no. Para quienes hayan habitado en tipologías edificatorias similares en otras ciudades de la región, será fácil encontrar tantas similitudes entre ellas y las que se diseñan, construyen y habitan en la actualidad en Lima, que difícilmente podrán afirmar que éstas últimas sean productos de arquitectura local.

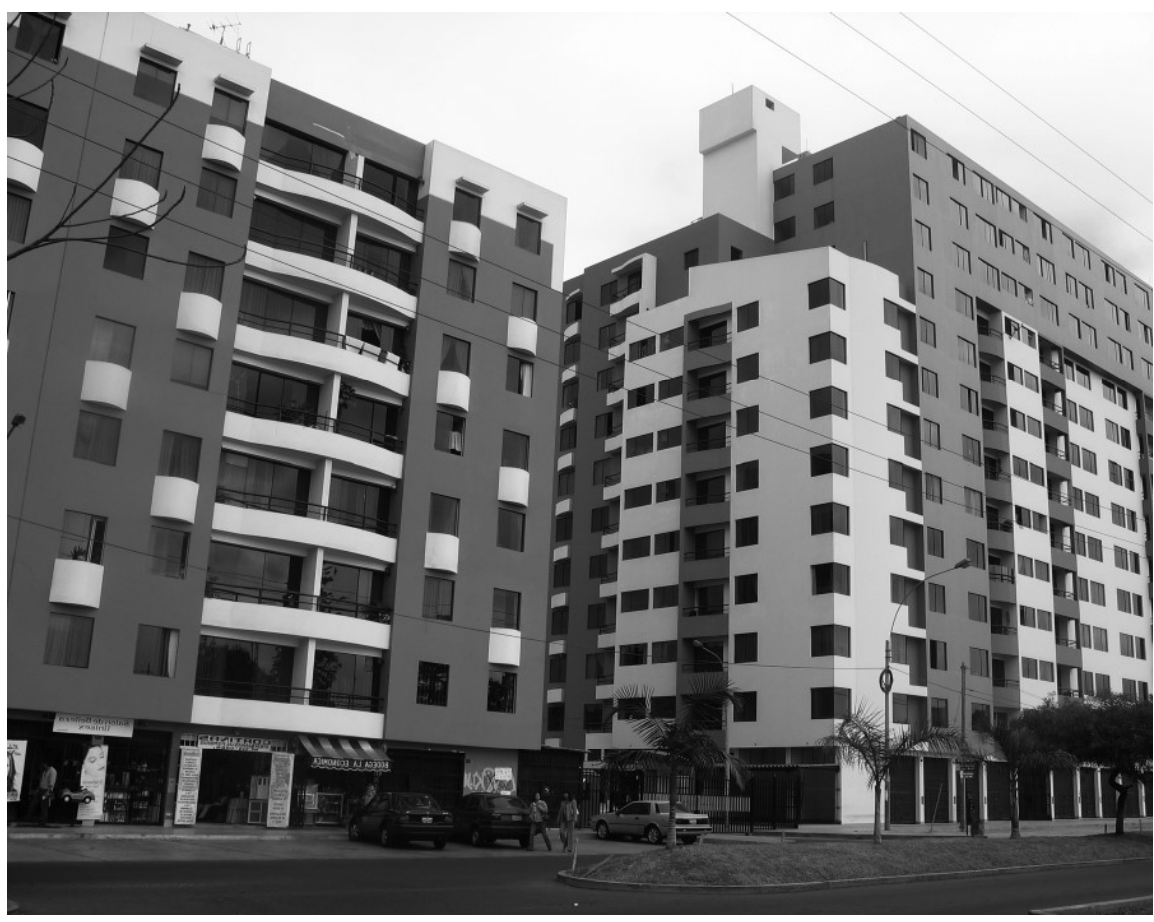




\section{Identidad arquitectónica}

La identidad arquitectónica es la síntesis de reconocimiento que cada colectivo hace de los valores y atributos físicos del objeto arquitectónico. Puede ser entendida como una descripción abstracta de un grupo de edificaciones con propiedades similares (atributos), comportamiento común (funciones), relaciones compartidas con el entorno y una semántica también común. Traduce en realidad, el grado de comunicación establecido entre lo construido y la población que lo habita. La identidad es imprescindible para el equilibrio y sentido de pertenencia de una comunidad urbana; por una parte cohesiona una imagen positiva de sí misma; y por otra, le permite adaptarse al entorno donde mora. Estas son dos funciones básicas que posee el concepto de identidad: una función de valoración de sí mismo y una función de adaptabilidad.

¿Es la identidad arquitectónica un concepto estático o, por el contrario, en construcción permanente? Pocos serán capaces de no reconocer que la identidad de lo construido en Lima cambia paulatinamente en el tiempo y que, en particular durante el último decenio, este cambio ha sido intenso. Sin duda, la identidad se forja por medio de un proceso de articulación permanente de lo nuevo con lo previo, de tal manera que lo nuevo es percibido en una relación aceptada y aceptable con lo existente. Integrando lo nuevo con lo preexistente se produce un cambio en la continuidad. El sentimiento de identidad permanece en tanto que la colectividad consigue dar a los cambios el sentido de continuidad.

La construcción de la identidad es una tarea colectiva meta consciente de una comunidad.

"Las identidades" ...pertenecen al mundo de las representaciones... apreciadas como un "...complejo sistema de percepciones -imaginarios, nociones, acciones, significados, significaciones y sentidosque mueven la praxis humana, la acción social..." (Guerrero: 2002, pág. 100).

Hasta el observador más distraído habrá podido observar el rápido y sostenido cambio del paisaje urbano de algunos sectores tradicionales de Lima. Allí donde nuestra memoria guardaba, hasta no hace mucho, imágenes de espacios bucólicos y sosegados, hoy se encuentra con una desenfrenada actividad constructiva que se expresa con desproporción en elevadas edificaciones residenciales y comerciales. Este es un fenómeno que se va extendiendo paulatinamente a sectores que percibíamos como detenidos en el tiempo.

\section{Obras de arquitectura o productos de arquitectura}

Para muchos observadores ilustrados, la arquitectura residencial contemporánea en Lima está viviendo una etapa de fabricación de productos de arquitectura, muy diferentes a los de otros momentos de su historia contemporánea en los que se construían obras de arquitectura. Aunque en ambos casos hablamos de arquitectura, la diferencia se encuentra, más que en el producto, en el modo de su producción. Desde las fases de ideación y diseño del producto residencial nos internamos en una línea de producción del tipo "fordista" en que lo importante es la eficiencia y eficacia de la repetición de la calidad del producto, antes que la singularidad de sus atributos.

Es difícil precisar si las inversiones inmobiliarias residenciales son causa o efecto del fenómeno del aumento inusitado del PBI nacional y del propio PBI del sector construcción en particular. Lo que sí es cierto, es que el eje central sobre el que gira vertiginosamente hasta ahora el mercado inmobiliario formal, ha sido la ejecución de un conjunto coherente de políticas gubernamentales en materia de vivienda, trazadas desde 2001.

En efecto, es a partir de la formulación y puesta en ejecución del Plan de Vivienda 20012006, cuando el Estado peruano modifica su estrategia redefiniendo su rol en términos de articulador y promotor de la actividad privada. Para el logro de este objetivo, el Estado modificó sustancialmente los marcos institucional y normativo del sector. Indudablemente a partir de la puesta en marcha del cambio de escala del Fondo Mi Vivienda es que se da inicio a la fase de expansión del presente ciclo del sector construcción. Esto es comprobable en las cifras del PBI del sector construcción que pasa a ser superior al PBI nacional a partir de 2002 (Salas: 2010).

El aparato productivo del sector construcción entra durante este período en un modelo económico de "acumulación flexible" en el cual los mercados masivos son indispensables para la aceleración del consumo (Harvey: 1998). La acumulación flexible ha permitido acelerar el ritmo de innovación del producto vivienda multifamiliar de alta densidad, además de explorar nichos de mercado más especializados.

La aspiración del mercado inmobiliario de producir masivamente viviendas requiere de estandarizar el producto para convertirlo en objetos idénticos, factibles de ser ensamblados en una línea de producción, tal cual un producto industrial de consumo masivo. Esta 


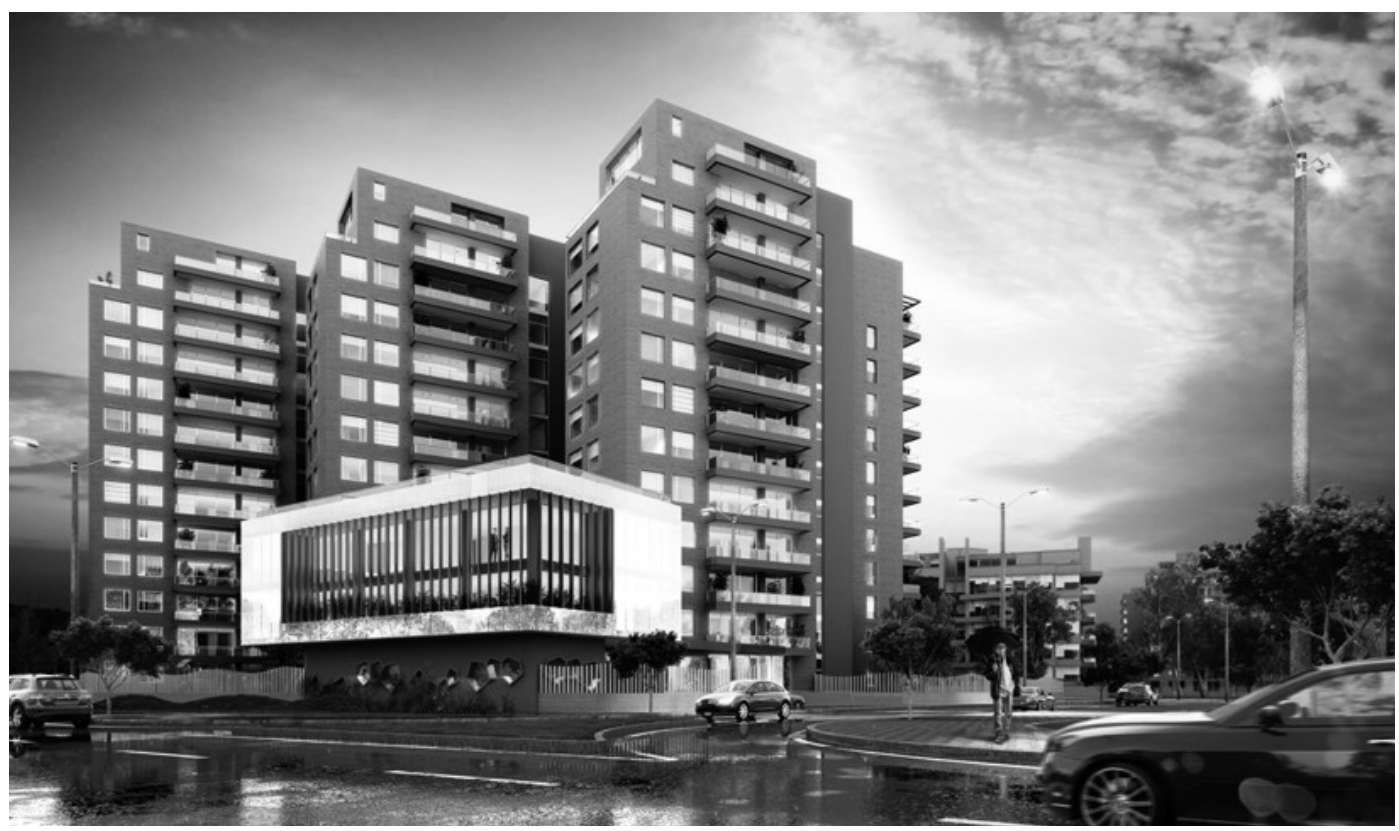

Fig. 1

Gran

Reserva

Trento.

Bogotá

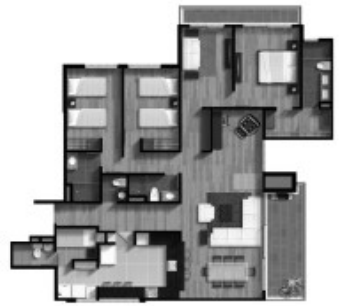

Fig. 2

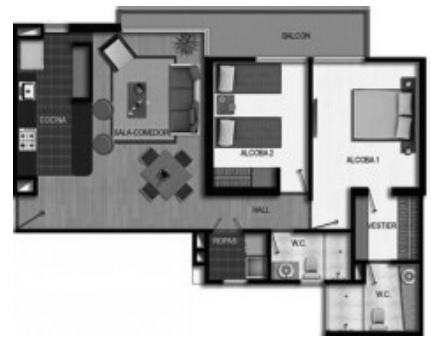

Fig. 5

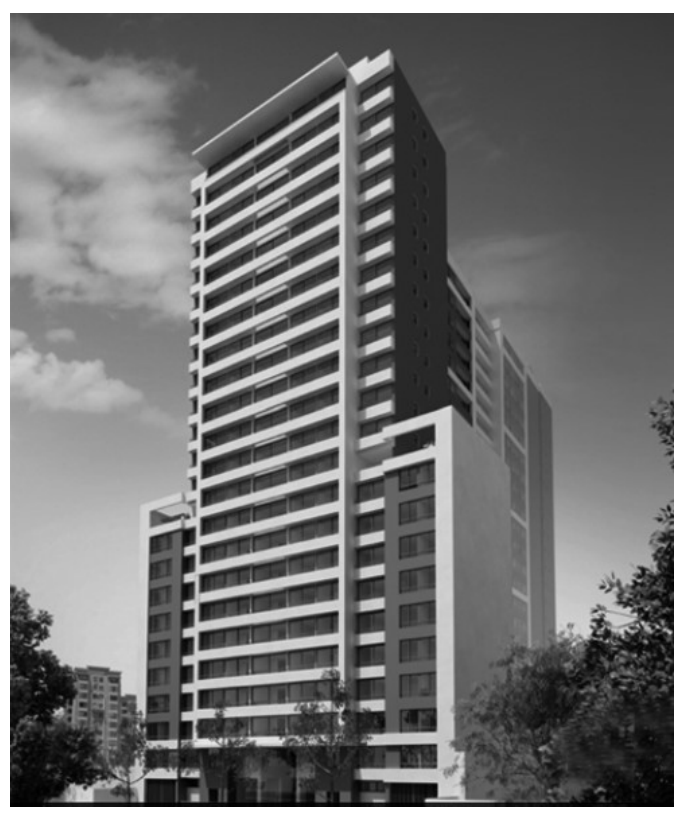

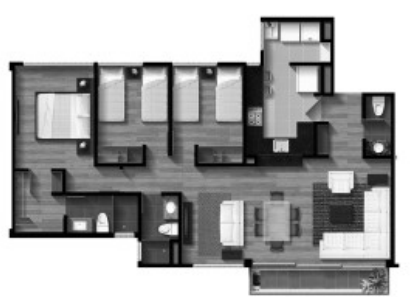

Fig. 3

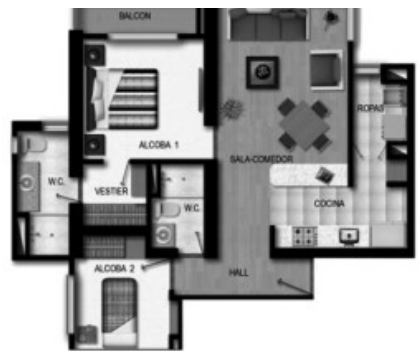

Fig. 6

Fig. 7

Proyecto

People

Santiago

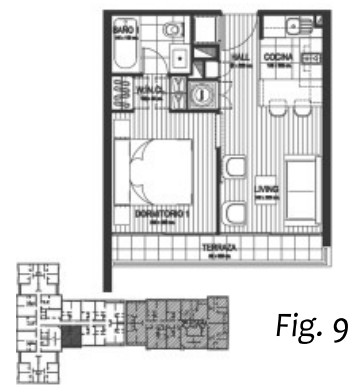

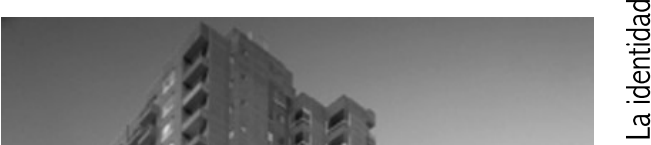

Fig. 8

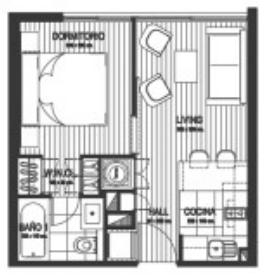

년

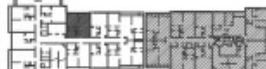

EI!

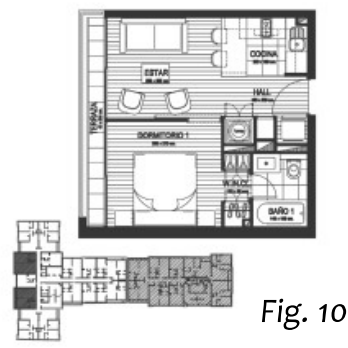


aspiración, por supuesto, es un simple deseo que dista mucho de la realidad del aparato de producción del sector. No obstante, la concentración de capital en torno a las empresas de mediano y gran tamaño ha significado un proceso de racionalización de los procesos constructivos.

En definitiva, la aspiración de convertir en masiva la producción residencial inmobiliaria en Lima parece estar encaminada al éxito. Por medio de la extensión del crédito hipotecario; la publicidad; una nueva psicología del consumo; las políticas gubernamentales; los cambios normativos de densidad, entre otros factores, se está generando una rápida y perceptible alteración del paisaje urbano limeño. Tipologías edificatorias ya ensayadas con anterioridad en otras ciudades latinoamericanas, son ahora ofrecidas al consumidor local. Existe un cambio de percepción de los consumidores de una Lima extendida de baja densidad (configurada por viviendas unifamiliares y departamentos en edificios de densidad media) por otra, en impetuoso proceso de crecimiento en altura, lo que ha significado sin duda, una mutación de las opciones del imaginario urbano local.

\section{Bogotá, Santiago y Lima}

El fenómeno descrito es muy similar al que atravesaran antes otras ciudades de países de la región con un modelo de desarrollo inmobiliario similar al que se instaló en Perú. En tal sentido, una expeditiva comparación de algunas alternativas que los mercados inmobiliarios de ciudades como Bogotá, Santiago y Lima ofrecen en la actualidad, puede interesar para determinar si la tipología edificatoria limeña presenta rasgos de singularidad que la identifiquen como producto local. Para este efecto, se visitó un conjunto de páginas electrónicas de empresas inmobiliarias de cada una de estas tres ciudades, con el objeto detectar, a través de estas publicaciones, los rasgos de similitud entre las diversas tipologías multifamiliares de alta densidad.

El análisis no perseguía una rigurosidad estadística sino simplemente la observación desaprensiva de las características de lo ofertado. Asimismo, no se tomaron en cuenta para el análisis, la gran cantidad de inversiones inmobiliarias de pequeña magnitud que se presentan en estas tres ciudades. A pesar de que fueron muchos más los proyectos inmobiliarios revisados, por razones de la extensión de esta publicación, solo algunos representativos son presentados a continuación.
Productos residenciales multifamiliares en Bogotá

Gran Reserva Trento. Bogotá

Gran Reserva Trento será un conjunto cerrado conformado por tres torres de 12 pisos, 3 apartamentos por piso, para un total de 106 apartamentos. En el piso 12 se encontrarán los pent-houses del proyecto. El conjunto contará con un acceso peatonal y vehicular por la Calle $24 \mathrm{C}$, dispondrá de planta eléctrica con cubrimiento en zonas comunes, tanque de reserva de agua y red de incendios. Cada una de las torres cuenta con dos ascensores, dos escaleras corta fuego, ductos de basura en cada piso y puntos fijos iluminados. (Fig. 1)

Algunos de los apartamentos tipo ofrecidos en este producto se muestran a continuación: Hall de acceso con baño social; sala-comedor; estudio; cocina abierta; zona de ropas independiente; alcoba principal con vestidor y baño privado y dos alcobas familiares con un baño auxiliar. $93 \mathrm{~m}^{2} \cdot 3 \mathrm{D} / 3 \mathrm{~B}$ (Fig. 2)

Sala-comedor; estudio con punto de chimenea a gas; balcón; cocina abierta; zona de ropas independiente; alcoba y baño de servicio; estar de alcobas; alcoba principal con vestidor y baño privado y dos alcobas familiares con un baño auxiliar. $123 \mathrm{~m}^{2}$. 3D/3B (Fig. 3)

\section{Kandinsky, Bogotá}

Este proyecto está conformado por 2 torres de 21 pisos y 3 torres de 30 pisos. Cada torre posee una circulación vertical con dos ascensores; áreas comunes de entretenimiento; dos canchas de squash; sala de internet; gimnasio; salón de reuniones; teatrín; áreas de juegos para niños; terraza con BBQ y miradores en cuatro de las torres. El conjunto está rodeado de espaciosas zonas verdes. El conjunto se encuentra cerca a importantes centros culturales y empresariales, escenarios deportivos, universidades y centros comerciales. (Fig.4)

Tipo: Apartamento. Área Construida: 85.3m². Alcobas: 2. Baños: 2 (Fig. 5)

Tipo: Apartamento. Área Construida: 72.2m². Alcobas: 2. Baños: 2 (Fig. 6)

\section{Productos residenciales multifamiliares} en Santiago

Proyecto People. Santiago

El concepto People es parte de una nueva generación de proyectos de la empresa Imagina (Bío Imagina), en los que además de ofrecer las convencionales áreas comunes equipadas, pretende corresponder a un mayor compromiso con el medio ambiente. Así, el proyecto publicita: WC con doble descarga, 


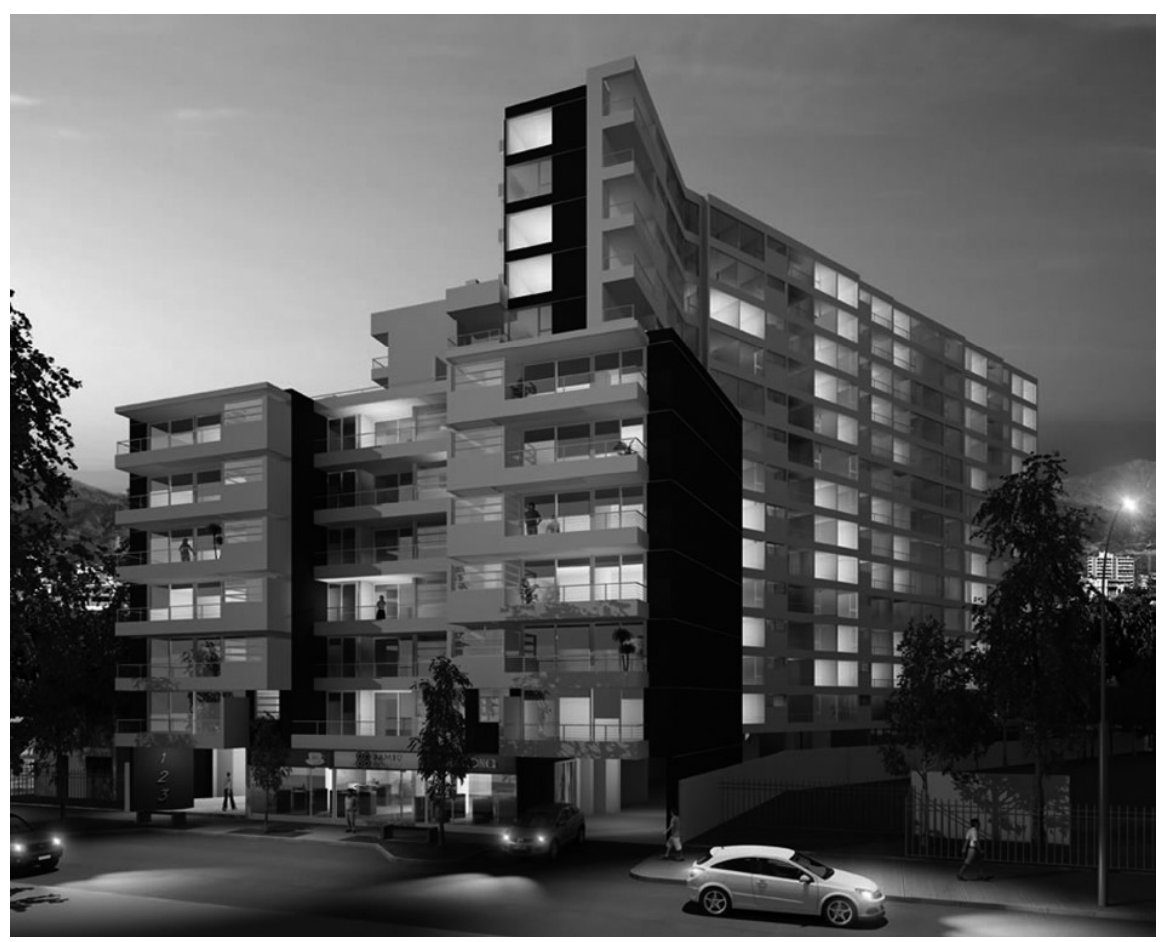

Fig. 11

Proyecto

Ñuñoa Migo.

Santiago

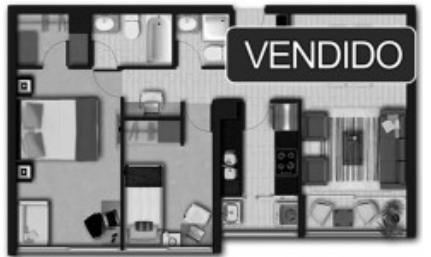

Fig. 12

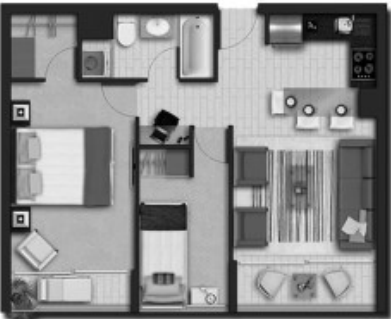

Fig. 13

Fig. 14

Proyecto Parque-Central,

Lima

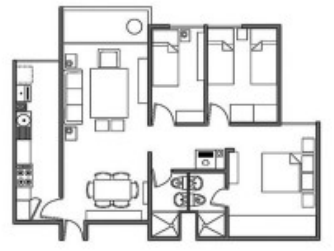

Fig. 15

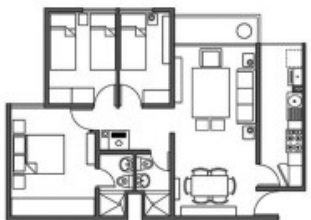

Fig. 16

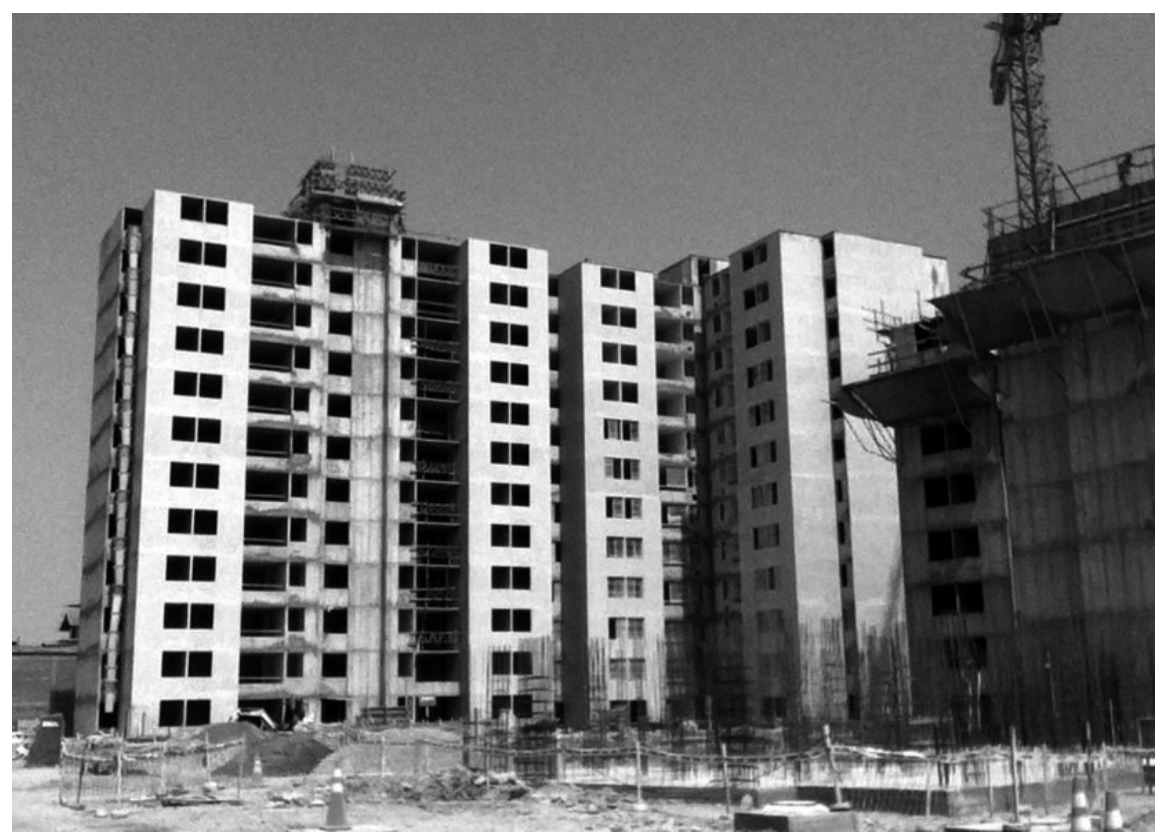

Fig. 17

Proyecto Parques de

San Martín de Porres.

Lima

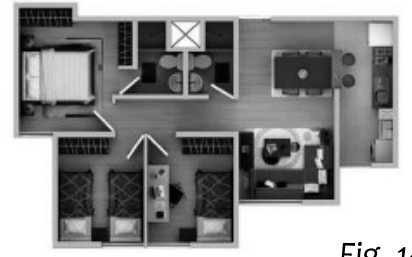

Fig. 18

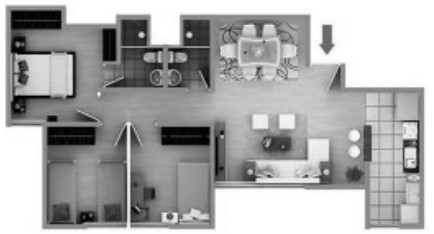

Fig. 19 
lo que permite reducir el consumo de agua; grifería con economizador de agua; focos ahorradores de energía y sensores de movimiento en escalera y pasadizos comunes para ahorro de energía. (Fig. 7).

Estudios de 1 y 2 dormitorios (Fig. 8, 9 y 10)

\section{Proyecto Ñuñoa Migo. Santiago}

Edificio Ñuñoa Migo se emplaza en una céntrica zona residencial de Ñuñoa, junto al tradicional sector de Plaza Egaña, en medio de un polo de desarrollo que está revitalizando a la comuna. El proyecto publicita: puertas de piso a cielo; enchapadas en madera natural; living-comedor y pasillos con porcelanato; dormitorios con alfombra; ambientes cálidos y agradables; acabado de porcelanato en todos los espacios de los departamentos de 1 dormitorio; cocina equipada con campana extraíble, encimera de vitro-cerámica, horno eléctrico y cubiertas de granito. (Fig. 11, 12 y 13)

\section{Productos residenciales multifamiliares en Lima}

Proyecto Parque-Central. Lima. (Av. Oscar R. Benavides)

Este importante proyecto asentado en una zona originalmente de uso industrial y recientemente re-zonificada y re-densificada en el Cercado de Lima, cuenta con 21 edificios que varían entre 12 y 15 pisos de altura. Cada uno de ellos alberga entre 4 y 8 departamentos por piso. Sus áreas fluctúan entre $67 \mathrm{~m}^{2}$ a $71 \mathrm{~m}^{2}$. Cuenta con alrededor de 15,000 m2 de parques y áreas verdes y 722 plazas de estacionamientos. (Fig. 14, 15 y 16)

Proyecto Parques de San Martín de Porres. Lima

Proyecto, producto de acumulación de lotes, en un área con una reciente re-zonificación y re-densificación. Ubicado en populosa área de San Martín de Porres, cuenta con 18 edificios de 5,10 y 12 pisos. Las áreas de los departamentos ofrecidos van desde 58,5 hasta $64,60 \mathrm{~m}^{2}$. Cuenta con 364 plazas de estacionamiento; área verde total del proyecto de $5177.88 \mathrm{~m}^{2}$. (Fig. 17, 18 y 19)

\section{Proyecto Life. Av. Brasil, Lima}

El concepto Life es otro de los proyectos de la empresa Imagina, en su aventura de inversión fuera de su país de origen, en el cual se ofrecen las convencionales áreas comunes equipadas y un variado menú de departamentos tipo. En efecto, el proyecto está configurado en dos torres de 20 y 15 pisos, que contienen 195 unidades habitacionales, que varían entre los $61 \mathrm{~m}^{2}$ y $83 \mathrm{~m}^{2}$ de superficie neta. Además, ofrece 199 plazas de estacionamiento vehicular. (Fig. 20, 21, 22 y 23)

\section{Proyecto Pacific. (Av. Costanera, Lima)}

El proyecto consta de cuatro torres de 15, 13, 12 y 9 pisos, con 166 plazas de estacionamiento y las convencionales áreas comunes equipadas. Bajo el mismo concepto Bío-Imagina, se publicita integrando las últimas tecnologías para apoyar el ahorro energético del consumo de recursos naturales y el reciclaje. Ofrece bicicletas para uso exclusivo de propietarios; focos ahorradores de energía, sensores de movimiento en escalera y pasadizos comunes para ahorro de energía y WC con doble descarga, lo que permite reducir el consumo de agua. (Fig. 24)

Los departamentos tienen superficies netas de aproximadamente: $60 \mathrm{~m}^{2}$ para los de 1 dormitorio; $70 \mathrm{~m}^{2}$ para los de 2 dormitorios y $82 \mathrm{~m}^{2}$ para los de 3 dormitorios. (Fig. 25, 26 y 27)

\section{Rasgos comunes y rasgos divergentes}

"La globalización está provocando un obsesivo afán de identidad, que va a provocar muchos enfrentamientos. Nuestras cabezas se mundializan, pero nuestros corazones se localizan."

Antonio José Marina

Es innegable que la arquitectura residencial contemporánea es esencialmente vista como un negocio que ha marcado activa y profundamente los rasgos de nuestra cultura urbana. Así se explica que el paradigma del consumismo haya convertido la percepción de la solución al problema de la vivienda, por lo menos en estratos socio-económicos medios y altos, en términos en que lo haría un consumidor inversionista, que ve el valor de cambio por encima del valor de uso del producto. Como mencionamos al inicio, esto parece estar asociado a la germinación de una nueva psicología de consumo, resultado de los objetivos ideológicos del modelo económico vigente.

Las empresas inmobiliarias han identificado un conjunto de signos en determinados estratos socioeconómicos limeños, que se manifiestan en su vocación colectiva, transferencia y perdurabilidad en el tiempo. Signos transferidos con habilidad a características identificables de la oferta inmobiliaria residencial actual, por medio de la introducción de un lenguaje global y los mecanismos propios de la mercadotecnia y la publicidad. De este modo, se legitima el logro de la valora- 


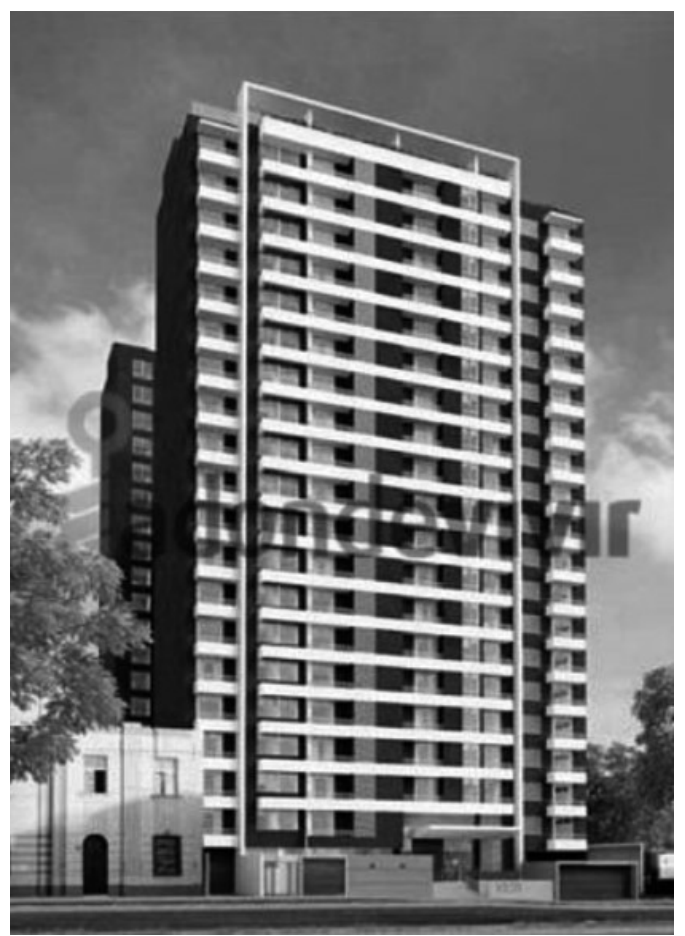

Fig. 20

Proyecto Life. Av. Brasil, Lima

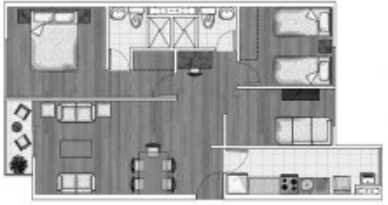

Fig. 22

Fig. 23

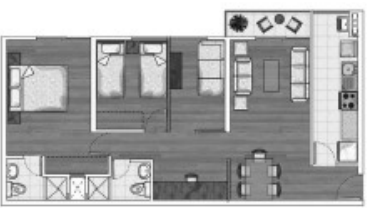

Fig. 21
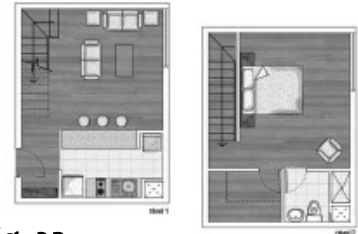

Fig. 24

Proyecto

Pacific.

Av.

Costanera, Lima

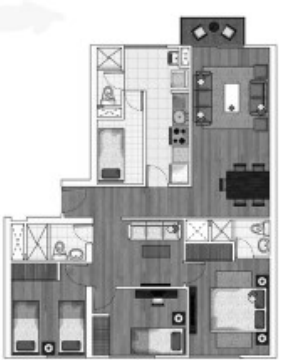

Fig. 26

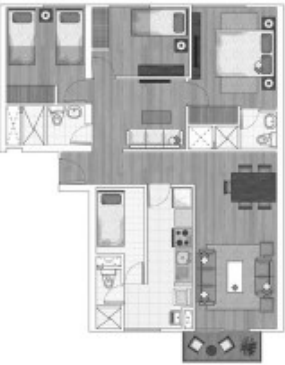

Fig. 27

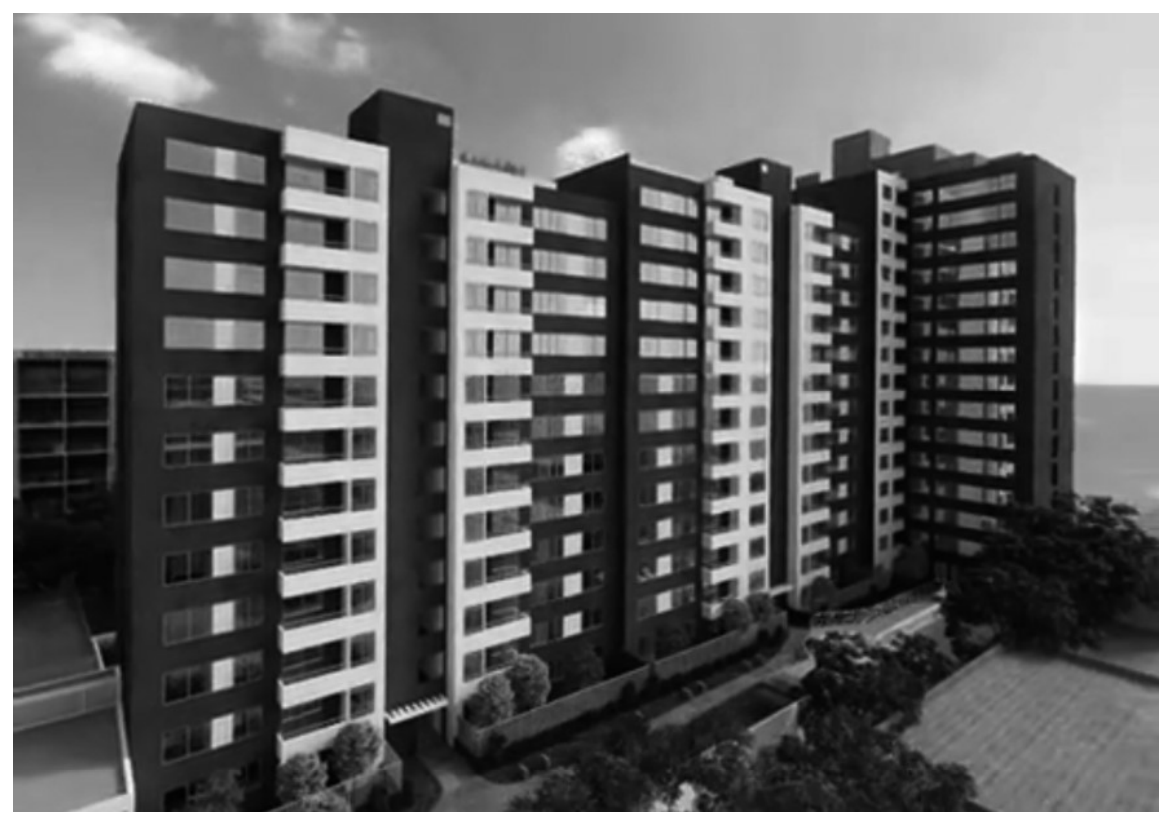

ción del consumidor de los signos arquitectónicos expresados en los productos ofrecidos.

A pesar de las naturales diferencias climáticas propias de las latitudes de localización de Bogotá, Lima o Santiago y de las particularidades de sus culturas locales, la oferta inmobiliaria parece haber encontrado y fabricado en estas ciudades, patrones tipológicos identificables y deseables por estratos socioeconómicos similares de la demanda. No hay más que repasar las imágenes arriba presentadas para observar la similitud de atributos de los productos residenciales, los que hasta en el modo de su presentación publicitaria, evidencian una relación de semejanza entre ellos.

Los rasgos formales de los mencionados patrones se manifiestan en un grupo de sig-

nos y códigos tipológicos que son asociados con pericia para orientar las preferencias del consumidor. En otras palabras, se ha logrado establecer una estructura de actitud en el imaginario colectivo de los diversos segmentos de mercado para estimular el consumo de los productos arquitectónicos de la oferta.

En torno a la localización se observaron rasgos comunes entre las tres ciudades. La oferta se orienta hacia lugares donde se perciba una atmósfera de protección y seguridad, signada por una específica segmentación de mercado que garantiza la homogeneidad del estrato socio-económico que lo habita.

En todos los casos, se observa cómo los modelos de unidades habitacionales respon- 
den a un criterio básico de "eficiencia". Efectivamente es notorio, en los ejemplos presentados, que la configuración funcional de los ambientes y sus superficies comparten rasgos comunes. Igualmente, es patente las semejanzas de solución en la organización de las plantas tipo.

Sobre la pertenencia, los mecanismos comunicacionales de la globalización han hecho posible que el imaginario colectivo (estratificado socioeconómicamente) se identifique con diversos detalles edificatorios antes que con la totalidad estructural de la edificación.

En el caso limeño, tales signos se presentaron en la semántica de comunicativos mensajes que contienen códigos de localización, pertenencia, uso y función. Por supuesto, igualmente en la valoración estética de rasgos tipológicos tales como los que se observan en: accesos a la edificación; características de la envolvente de llenos y vacíos; tratamiento de las aristas de los volúmenes; preferencias cromáticas; en ciertos casos, los remates de los planos de fachada $y$, naturalmente, el empleo de materiales de acabados.

Hoy, tal como siempre ha sido, aunque con diferentes intensidades, se viven tiempos en los cuales actúan fuerzas en permanente búsqueda de transformaciones y cambios. Transformaciones, que se dan de manera fragmentada y que se suceden en un ambiente de brevedad con cortos tiempos de vida. Consecuentemente, la producción arquitectónica debe ser vista como un lenguaje simbólico que se construye paulatina y permanentemente y que refleja las variaciones del pensamiento de la sociedad en su transcurrir.Entonces, antes de polemizar sobre lo apropiado de las particularidades de una suerte de identidad oficial de la arquitectura residencial de alta densidad en Lima, se debe afrontar el reto de descubrir si tales productos de arquitectura habitacional son una respuesta adecuada y perdurable a las reales necesidades generacionales de satisfacción de consumo de los habitantes de la Lima actual. Negar la relevancia de la influencia del proceso de globalización en el comportamiento del consumidor limeño sería ilusorio. Batallar contra ella, desde una postura exclusivamente localista de identidades culturales excluyentes y chauvinistas, también lo sería. Ver, por el contrario, la globalización como un proceso cultural ecuménico en el que el intercambio de experiencias y producción culturales, son un patrimonio de todos, parece ser una actitud acertada. La heterogeneidad de lo diverso es riqueza y como tal debe ser compartida por todos los segmentos sociales sin distinción de su localización y origen.

La demostración de la conjetura inicial sobre la inexistencia de una identidad particular de la arquitectura residencial multifamiliar de alta densidad en Lima es evidente. Sin embargo, queda por reflexionar sobre la probabilidad que se pueda estar gestando una arquitectura multifamiliar con singularidades regionales.

\section{Referencias bibliográficas}

GUERRERO ARIAS, Patricio. Usurpación simbólica, identidad y poder. Ediciones Abya-Yala-Corporación Editora Nacional, Universidad Andina Simón Bolívar, Quito, 2002, pág. 100.
HARVEY, David. La condición de la posmodernidad: investigación sobre los orígenes del cambio cultural. Amorrortu Editores, Buenos Aires, 1998.
SALAS C., Juan de Dios. La expansión en el sector construcción y su impacto en Lima. Paideia XXI Vol. $1 N^{\circ}$ 1, Universidad Ricardo Palma, Lima, 2010.

\section{Direcciones electrónicas}

CONSTRUCTORA CUSEZAR. Proyecto inmobiliario Gran Reserva de Trento.

http://www.cusezar.com/proyectos/gran-reserva-de-trento (Consulta: 04-05-2013).

CONSTRUCTORA CUSEZAR. Proyecto inmobiliario Kandinsky. http://www.cusezar.com/proyectos/kandinsky (Consulta: 0405-2013).

IMAGINA. Proyecto concepto People. http://www.imagina.cl/proyecto/
Concepto+People. (Consulta: 0405-2013).

RALEI. Edificio Ñuñoa Migo. http://www.ralei.cl/edificio-nunoamigo/edificio-en-venta.html. (Consulta: 04-05-2013).

VIVA G y M. Proyecto Parque Central Club Residencial.

http://www.vivagym.com.pe/ info_proyecto.aspx?id=. (Consulta: 04-05-2013).

VIVA G y M. Proyecto LOS Parques de San Martín de Porres. http://www.vivagym.com.pe/ info_proyecto.aspx?id=8. (Consulta: 04-05-2013).

IMAGINA. Proyecto concepto Life. http://www.imagina.com.pe/ proyecto-bio.php?idpry=31. (Consulta: 04-05-2013).

IMAGINA. Proyecto concepto Pacific.

http://www.imagina.com.pe/ proyecto-bio.php?idpry $=29$. (Consulta: 04-05-2013). 